\title{
The quasi-perpetual electricity generating device based on ceramic fuel cell for closed systems
}

\author{
Yurii Basaraba $^{\mathrm{a}^{*}}$, Mykolay Brychevskyi ${ }^{\mathrm{b}}$, Yehor Brodnikovskyi ${ }^{\mathrm{b}}$, Oleksandr Vasylyev ${ }^{\mathrm{b}}$, Ivan \\ Perekopskyi ${ }^{\mathrm{c}}$ \\ ${ }^{a}$ Department of General and Applied Physics, Ivano-Frankivsk National Technical University of \\ Oil and Gas, Karpatska Street, 15, Ivano-Frankivsk 76019, Ukraine \\ ${ }^{\mathrm{b}}$ Department of Physics of Strength and Plasticity of Materials, Institute for Problems of Materials \\ Science, Krzhizhanovsky Street, 3, Kyiv 03680, Ukraine

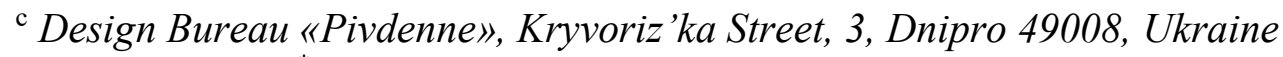 \\ *Contactinge-mail: yubasaraba@ukr.net
}

Keywords: ceramic fuel cell, high temperature electrolysis, hydrogen production, system efficiency

The features of ceramic fuel cells developed in Ukraine are discussed and their application for production of hydrogen and oxygen in a closed loop device combining ceramic fuel cells (CFC) and ceramic electrolyser cells (CEC) is considered. High-temperature electrolysis is profitable for production of hydrogen and oxygen from hot water steam, that is outcoming gas of CFC's reactions and released traditionally in environment, as it is demonstrated theoretically.

\section{Introduction}

Ceramic fuel cell (CFC), named traditionally as solid oxide fuel cell (SOFC), is proposing the highest amount of electric energy released at reactions between chemical elements. As the most impressive are zirconia ones, those may generate electric energy using hydrogen as a fuel and oxygen from air at $\sim 95 \%$ efficiency. They may operate at $600{ }^{\circ} \mathrm{C}$ and for above 70000 hours [1]. To produce electricity, they need in gaseous hydrogen or hydrocarbons etc. and oxygen from air only. Their by-products are heat, that originally may consist of around 1/
$3 r d$ of all the energy released, and pure water. $1 \mathrm{~kg}$ of water is produced at generation of $\sim 4.5 \mathrm{~kW} \cdot h$ of electric power.

Fuel cell is able principally to operate in reverse manner. Being as electrolyzer, reversible ceramic fuel cell (RCFC) may efficiently produce gaseous hydrogen and oxygen being supplied by water and electricity [2].

Currently, electrical efficiency of CFC itself is $\sim 65 \%$ of the released energy. The concomitant heat power may be converted into electrical one by mechanical or thermoelectric converters. As result, general efficiency of CFC system is $\sim 95 \%$. 
CFCs are now in the process of their structural optimization, the goal of which is to achieve the named figures at mass production [1]. For the last few years, we have witnessed major technological advances and competition of major energy companies within the evolving fuel cell market. General Electric, one of the fuel cell pioneers that provided energy for the first space missions, is planning now to enter the fuel cell market with their CFC system. GE has claimed a recent fuel cell breakthrough with an unprecedented electrical efficiency of $65 \%$ and an overall efficiency of up to $95 \%$ when their system is configured to capture heat produced by the fuel cell process that allowed GE to claim that "the resulting technology could soon start producing electricity around the world" [3].

In Ukraine, the data accumulated in Laboratory for Ceramic Fuel Cells at Frantcevych Institute for Problems of Materials Science indicate undoubtedly that the structure of CFC might be optimized for purposes of both maximal efficiency and prolonged use. The main achievements, which led the authors to understanding that CFC structural optimization would be realized are as follows [1]:

The ionic conductivity of bulk and film electrolytes made of Ukrainian $1 \mathrm{Ce} 10 \mathrm{ScSZ}$ powder is $0.035 \mathrm{~S} \cdot \mathrm{cm}^{-1}$ at $700{ }^{\circ} \mathrm{C}$ instead of the $0.010 \mathrm{~S} \cdot \mathrm{cm}^{-1}$ obtained with the best powders available at international scale. Electrolytes made of our powder has the highest strength $(450 \mathrm{MPa}), \quad$ fracture toughness
1.2 - $1.7 \mathrm{MPa} \cdot \mathrm{m}^{1 / 2}$. The Ukrainian electrolyte is much less inclined to recrystallization at long term operation.

The ionic conductivity of electron beam physical vapor deposition (EB-PVD) electrolyte films deposited onto a porous $\mathrm{NiO}-\mathrm{ZrO}_{2}$ anode substrate is higher (half an order of magnitude) than of layers deposited, e.g., by typical screen printing.

CFC made with EB-PVD electrolytes were the first to pass the severe Juelich Research Center, Germany, standard for He leakage rate below $10-4 \mathrm{mbar} \cdot \mathrm{cm}^{-2} \cdot \mathrm{s}^{-1}$, and has demonstrated an area specific resistance (ASR) of $\sim 0.6 \mathrm{ohm} \cdot \mathrm{cm}^{2}$ at $600{ }^{\circ} \mathrm{C}$.

The laboratory fuel cells made of gadolinia doped ceria electrolyte have demonstrated $\sim 0.04 \mathrm{~W} / \mathrm{cm}^{2}$ being fueled by model gas $-5-$ vol. $\%$ with Ar at $650{ }^{\circ} \mathrm{C}$. I.e., with right designed electrodes, which could ensure the linear dependence of electric current on non-diluted hydrogen fuel, such the fuel cell may provide $\sim 0.80 \mathrm{~W} / \mathrm{cm}^{2}$ with $100 \%$ hydrogen. The available literature data shows $\sim$ $0.82 \mathrm{~W} / \mathrm{cm}^{2}$ as a typical power but at $750{ }^{\circ} \mathrm{C}$.

The structural optimization might be easily realized, if all the steps of a long CFC creation process could be united under one research project acting under the "from powder to power" concept, i.e., it begins from powder synthesis and completes by CFC testing via comprehensive structural characterization of powders and their transfer into CFCs, behavior 
characterization of their electrical and mechanical properties in different gas environment and at different mechanical and electrical loadings, catalytic activity both electrodes and their new concepts, integration into technically relevant cells and stacks, and long-term tests.

Finally, at the last stage of the study, the stage of the "positive degradation", using data obtained for powders and CFC, materials will be modified and optimized in order to get a positive effect on the CFCs long-term performance at their usage in energy systems.

The CFC, which has no any delaminating cracks along contacts between its structural parts that is very important for any electrotechnical device, might be elaborated [4].

Regarding the use of hot outcoming water steam, it is known that the efficiency of the electrolyzer is increasing with temperature reaching $100 \%$ at around $900^{\circ} \mathrm{C}$ [5]. It means that both $600{ }^{\circ} \mathrm{C}$ CFCs and their electrolyzers might be efficiently used in electricity generating devices in order to supply any closed system.

An imagination is painting some quasiperpetual energy system for any spacecraft, which could be launched with energy produced by CFC from some initial amount of hydrogen and oxygen. The CFC by-product, water steam, is decomposed for $\mathrm{H}_{2}$ and $\mathrm{O}_{2}$ with the $\mathrm{CFC}$ electrolyzer to be supplied by electricity produced by solar or thermoelectric cells. $\mathrm{H}_{2}$ and $\mathrm{O}_{2}$ gases will be stored and further re-used for production of electricity with no any water losses in the closed system. In such a way, the accumulation and the storage of electric power will be solved via gaseous way. Energy losses would be compensated by Sun, which might bestow the required energy

High Temperature Steam Electrolysis (HTSE), based on CFC is a promising way to produce hydrogen with high efficiency [1]. Solid oxide electrolytes are the basis of two important energy technologies CFC and CEC. CFC offers an efficient alternative to combustion technology for electricity production and, similarly, CEC offers enhanced efficiency in the conversion of steam and carbon dioxide to hydrogen and carbon monoxide, respectively $[2,6]$.

The goal of the paper is to analyze the joint opportunity of RCFC based on available developments and scientifical principles to be put in their basement. As to CFC, we see from the above that highly efficient durable fuel cell is developed and might be produced. As to CES, the situation is not so obvious yet. The features of high-temperature electrolysis and the possibility of creating a closed loop CFC - CEC device in order to generate electricity must be considered.

\section{On the efficiency of high temperature electrolysis}

Electrolysis is a well-known process splitting water $\left(\mathrm{H}_{2} \mathrm{O}\right)$ into hydrogen $\left(\mathrm{H}_{2}\right)$ and oxygen $\left(\mathrm{O}_{2}\right)$ by using electrical energy $[7,8]$. 
Historically, the very idea of a fuel cell has been originated from experiments on electrolysis of water by British scientists Humphrey Davy and others as the answer on one fundamental question - if the water does release hydrogen and oxygen at immersing electrical electrodes into it, probably, some process producing electricity exists also if oxygen and hydrogen could be united [6, 9]. William Nicholson and Anthony Carlisle had described the process of using electricity to decompose water into hydrogen and oxygen. Judge and scientist, Sir William Robert Grove in his experiments on electrolysis in 1839 - the use of electricity to split water into hydrogen and oxygen - led to the first mention of a device that would later be termed as the fuel cell. Grove reasoned that it should be possible to reverse electrolysis process and generate electricity from the reaction of oxygen with hydrogen.

The electrolysis of water provides clean (99.6 - $99.9 \%)$ hydrogen and oxygen in one technological stage. Its economics depends on the electricity cost mainly.

High temperature may obviously lighten the decomposition of water. The hightemperature electrolyzers that operate at temperatures above $1000 \mathrm{~K}$ have an efficiency approaching to $100 \%$ [1-3]. This result gives an opportunity to assume that electrolyzers in combination with high-temperature fuel cells may allowing to untie the row of important tasks in the areas of energetics, and, in a separate case, the task of creation of powerful electricity accumulating devices based on fuel cells.

As the product of $\mathrm{CFC}$ reaction is hot water steam $\left(600^{\circ} \mathrm{C}\right.$ or higher), it means that applying some electric energy from additional external source, e.g., solar, or thermoelectric cell, to outletting CFC steam we could split up water into hydrogen and oxygen more easily.

In accordance with the total equation of water splitting process

$$
\mathrm{H}_{2} \mathrm{O} \rightarrow \mathrm{H}_{2}+\frac{1}{2} \mathrm{O}_{2}
$$

in order to get $1 \mathrm{~m}^{3}(90 \mathrm{~g})$ hydrogen $810 \mathrm{~g}$ of water and $2394 A \cdot h$ of electricity are required. Electric power, $W_{e l}$, which will be spent in this process, is the product of electricity amount on the electrolyzer cell voltage, $U$

$$
W_{e l}=2.394 \cdot U
$$




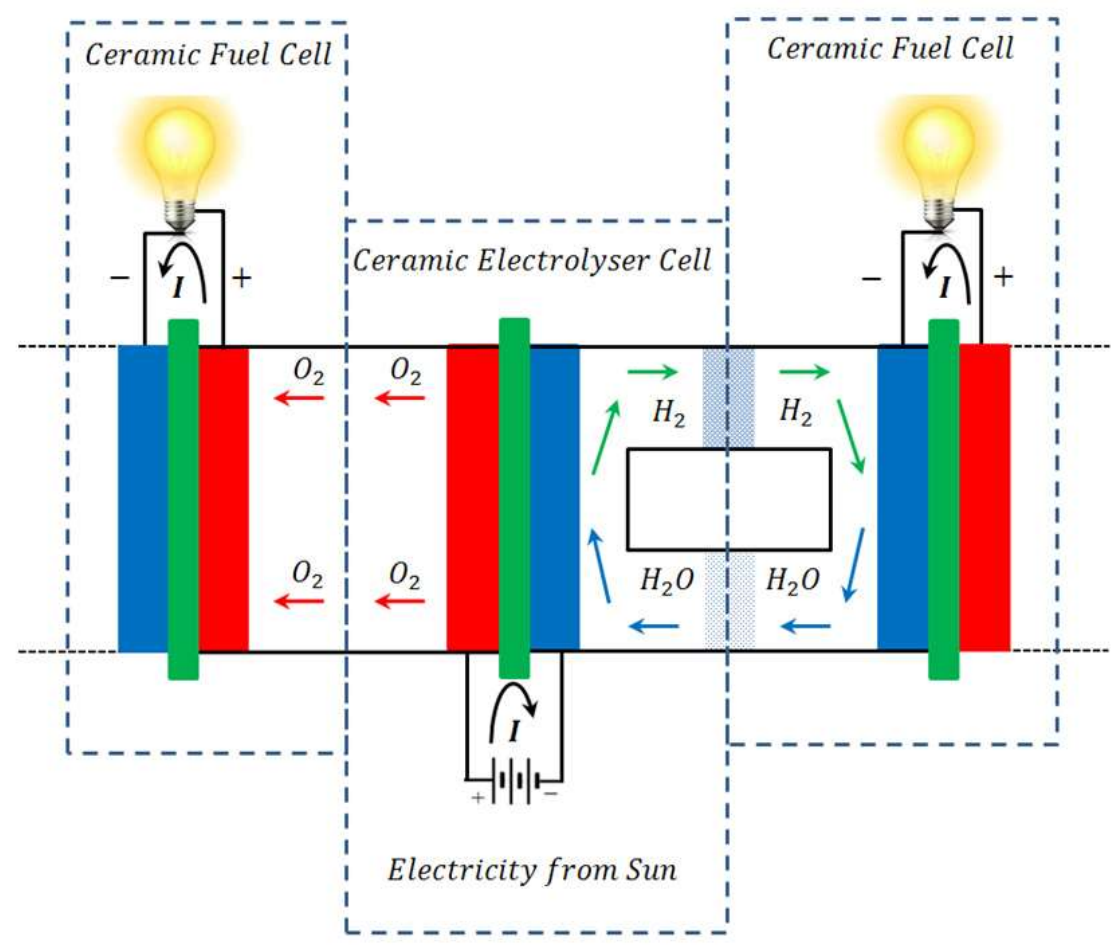

Figure 1. The scheme of the reserved cycle with fuel cell and electrolyzer.

Theoretical value of the electromotive force (EMF) of the cell $E_{\mathrm{T}}$, which is necessary to realize the reaction of water splitting, is as follows:

determined as follows:

$$
E_{\mathrm{T}}=-\frac{\Delta G}{n \cdot F}
$$

where $\Delta G$ - the change of free Gibbs energy, $\Delta G_{298 \mathrm{~K}}=237190 \mathrm{~J} / \mathrm{mole}$ [7]; $n$ - number of electrons, which participate in an electrode reaction; $F$ - Faraday's constant. This part of the energy is considered as a work done by electricity.

The theoretical value of electrical voltage necessary to split water into oxygen and hydrogen is $1.23 \mathrm{~V}$.
The splitting process is endothermic, therefore, some heat must be supplied to the cell,

$$
Q=T \Delta S=\Delta H-\Delta G
$$

Otherwise, the cell will cool down.

The thermal effect of water splitting reaction equals $\Delta H$ and is the sum of work and heat, which is spent in the process.

The cell voltage corresponding to this thermal effect is

$$
E_{q}=\frac{\Delta H}{n \cdot F}
$$

and is named as the thermoneutral voltage. It equals the cell voltage in a hypothetical isobarisothermal circulating process, at which there is 
no heat and mass exchange with the environment and all necessary energy (sum of necessary heat and work) for the reaction is supplied as electric power. Since the thermal effect of water splitting $\Delta H$ depends on temperature very weakly, $E_{q}$ does not change practically and at the water electrolysis considering the heat of evaporation equal $E_{q}^{\prime}=1.481 \mathrm{~V}$, and at the electrolysis of water steam of $E_{q}^{\prime \prime}=1.25 \mathrm{~V}$.

The part of work to split water in ratio to the general energy expenditures at an electrochemical process, $\eta=E_{T} / E_{q}$, and as $E_{T}$ for water diminishes with increasing temperature (at atmospheric pressure $\frac{\partial E_{T}}{\partial T}=-0.25 \mathrm{mV} / \mathrm{K}$ [7]), the part of heat grows, and at $T \approx 5000 \mathrm{~K}$ all energy necessary for the water splitting is practically used as a heat $(\eta \approx 0)$.

The dependence of $E_{T}$ and other parameters of reaction on temperature is driven to the (Table 1), where theoretical values of $W_{T}^{e l}$ and $W_{T}^{\text {heat }}$ are found as

$$
\begin{gathered}
W_{T}^{e l}=2.394 \cdot E_{T}=2.394 \cdot E_{q} \cdot \eta \\
W_{T}^{\text {heat }}=2.394 \cdot\left(E_{q}-E_{T}\right)= \\
=2.394 \cdot E_{q} \cdot(1-\eta) .
\end{gathered}
$$

Table 1. Theoretical values of electromotive force (EMF) and expenditures of energy in the reaction of water splitting at $p=0,1 \mathrm{MPa}$ (for temperatures 298 and $353 \mathrm{~K}$ is an electrolysis of water, for higher temperatures - an electrolysis of steam) electrolysis of water together with the outlay of electric power, the direct transformation of heat that is provided to the cell is fundamentally possible in chemical energy of fuel-oxidizing mixture (hydrogen and oxygen) in an amount of $W_{T}^{\text {heat }}$.

The change of $E_{T}$ and $E_{q}$ is shown in Fig. 2 in dependence on temperature at atmospheric pressure. At cell voltage of $U<E_{T}$ (area 1), production of hydrogen from water by electrolysis is impossible. At $E_{T}<U<E_{q}$, electrolysis requires heat to be supplied, e.g., from environment. The water decomposition requires not only electric power but thermal one also (areas 2 and 3) in an amount

$$
Q=\left(E_{q}-U\right) n F
$$

where $E_{q}=E_{q}^{\prime}$ at the electrolysis of water and $E_{q}=E_{q}^{\prime \prime}$ at the electrolysis of steam.

In the area of $E_{\mathrm{T}} \leq U \leq E_{q}^{\prime \prime}$ (area 2), at the electrolysis of steam, the heat that could be supplied from outside is spent directly on the decomposition of molecules of water, and at the electrolysis of liquid water - both on evaporation and decomposition of water. 


\begin{tabular}{|c|c|c|c|c|c|c|c|c|}
\hline \multirow{2}{*}{ Parameter of reaction } & \multicolumn{9}{|c|}{$T, \mathrm{~K}$} \\
\cline { 2 - 9 } & 298 & 353 & 423 & 473 & 573 & 773 & 1273 & 2273 \\
\hline$E_{T}, V$ & 1,23 & 1,18 & 1,15 & 1,10 & 1,04 & 0,95 & 0,80 & 0,50 \\
\hline$\eta$ & 0,83 & 0,80 & 0,92 & 0,88 & 0,83 & 0,76 & 0,64 & 0,40 \\
\hline$W_{T}^{\text {el }}, \mathrm{kW} \cdot \mathrm{h} / \mathrm{m}^{3}$ & 2,94 & 2,82 & 2,75 & 2,63 & 2,49 & 2,27 & 1,91 & 1,20 \\
\hline$W_{T}^{\text {heat }}, \mathrm{kW} \cdot \mathrm{h} / \mathrm{m}^{3}$ & 0,60 & 0,72 & 0,24 & 0,36 & 0,5 & 0,72 & 1,08 & 1,79 \\
\hline
\end{tabular}

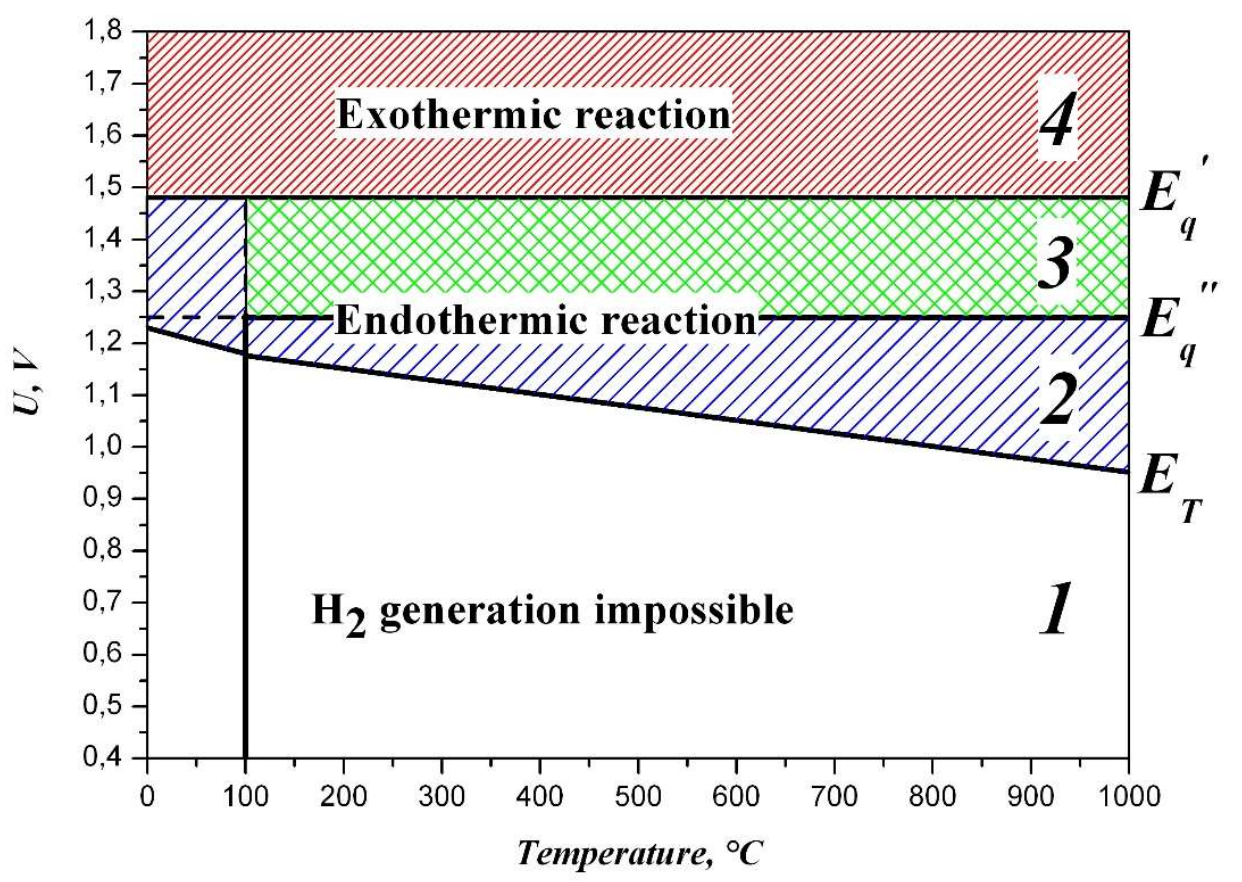

Figure 2. Conditions for the realization of electrolysis.

In the area of $E_{q}^{\prime \prime} \leq U \leq E_{q}^{\prime}$ (area 3), at the electrolysis of water, the heat supplied from external sources is spent on evaporation of water; at the electrolysis of steam, this heat scatters in an environment.

In the area 2, electric power for the electrolysis is less than lower heating value of combustion of hydrogen in oxygen, and in the area of $3,-$ it is higher than lower heating value, but less than higher heating value. At $U>E_{q}^{\prime}$, the heat that is given off in the cell spreads in environment and expenditures of electric power on the production of hydrogen exceed the higher heating value of combustion of the fuel-oxidizing mixture formed (area 4). It is clear thermodynamically that the process of hightemperature electrolysis is more advantageous and values of $U$, near to $E_{T}$, with supply of heat from external source.

Thus, the voltage of water splitting is decreased when the temperature is increased.

As result, at high-temperature electrolysis, the considerable economy of electric power occurs and its efficiency do increase. Expenses of energy diminishes from $4.5 \mathrm{~kW} \cdot h$ to $3 \mathrm{~kW} \cdot h$ per $1 \mathrm{~m}^{3}$ hydrogen. 


\section{Conclusions}

The data available and discussed indicate obviously that the quasi-perpetual energy system based on reversible ceramic fuel cells for closed systems like space planes or unmanned aerial and navy vehicles looks as possible both thermodynamically and technically. Hot water steam electrolysis requres less electric power for $\sim 33 \%$, diminishing from $4.5 \mathrm{~kW} \cdot h$ to $3 \mathrm{~kW}$. $h$ per $1 \mathrm{~m}^{3}$ hydrogen.

\section{Acknowledgements}

We are grateful to the National Academy of Science of Ukraine, their projects "Structural Fundamentals of Materials for Zirconia Ceramic Fuel Cells" and "SOFC structural optimization based on consideration of interdiffusion at manufacturing and operation", and current ones; NATO, their "Science for Peace" project №980878 “Solid Oxide Fuel Cells for Energy Security”, the European FP6 projects: №SES62006-020089 "Demonstration of SOFC stack technology for operation at $600{ }^{\circ} \mathrm{C}$ (SOFC600)" and students exchange program of the "RealSOFC", INTAS project "Structure Optimization of SOFC Based on Scandia Doped Zirconia Ceramics for Space Application" for their respective supports.

\section{References}

[1] Reytier M, Di Iorio S, Chatroux A, Petitjean M, Cren J, De Saint Jean M, Aicart
J, Mougin J. Stack performances in high temperature steam electrolysis and coelectrolysis. Int. J. Hydrogen Energy 2015;40:11370-11377.

[2] Irvine JTS, Neagu D, Verbraeken $\mathrm{MC}$, Chatzichristodoulou $\mathrm{Ch}$, Graves $\mathrm{Ch}$, Mogensen MB. Evolution of the electrochemical interface in high-temperature fuel cells and electrolysers. Nature Energy 2016;1:1-13.

[3] Jin L, Guan WB, Ma X, Xu Ch, Wang WG. Achieving Hydrogen Production through Solid Oxide Electrolyzer Stack by High Temperature Electrolysis Solid Oxide Electrochemical Cells. ECS Transactions 2012;41(33):103-111.

[4] Vasylyev O, Brodnikovskyi Ye, Brychevskyi M, Polishko I. From powder to power: Ukrainian way. In this journal issue.

[5] Appel ChC. Zirconia stabilized by Y and Mn: A Microstructural Characterization. Ionics 1995;1(5-6):406-413.

[6] Mobius HH. On the history of solid electrolyte fuel cells, J Solid State Electrochem. 1997;1: 2-16.

[7] Wendt $\mathrm{H}$, Electrochemical Hydrogen Technologies: Electrochemical Production and Combustion of Hydrogen. Amsterdam - New York: Elsevier; 1990. pp. 139-142.

[8] Zeng K, Zhang D. Recent progress in alkaline water electrolysis for hydrogen production and applications. Progress in Energy and Combustion Science 
2010;36(3):307-326.

[9] Majumdar H. Fuel Cell History, The University of Toledo, Toledo, Ohio, USA.

In:http://educypedia.karadimov.info/library/sofc final8.swf. 